\title{
Time to Antibiotics in Pediatric Patients with Fever in Neutropenia during Chemotherapy for Cancer - Data from the Prospective Multicenter SPOG 2015 FN Definition Study
}

\author{
Christa Koenig ${ }^{1}$, Claudia Kuehni ${ }^{2}$, Nicole Bodmer ${ }^{3}$, Philipp Agyeman ${ }^{1}$, Marc Ansari ${ }^{4}$, \\ Jochen Rössler ${ }^{1}$, Nicolas von der $\mathrm{Weid}^{5}$, and Roland Ammann ${ }^{1}$ \\ ${ }^{1}$ Inselspital University Hospital Bern \\ ${ }^{2}$ University of Bern Institute of Social and Preventive Medicine \\ ${ }^{3}$ University Children's Hospital Zürich \\ ${ }^{4}$ University Hospitals of Geneva Child and Adolescent Department \\ ${ }^{5}$ University Children's Hospital Basel
}

July 21, 2021

\begin{abstract}
Background. Fever in neutropenia (FN) remains an unavoidable, potentially lethal complication of chemotherapy. Timely administration of empirical broad-spectrum intravenous antibiotics has become standard of care. But the impact of time to antibiotics (TTA), the lag period between recognition of fever or arrival at the hospital to start of antibiotics, remains unclear. Here we aimed to analyze the association between TTA and safety relevant events (SRE) in data from a prospective multicenter study. Procedure. We analyzed the association between time from recognition of fever to start of antibiotics (F-TTA) and SRE (death, admission to intensive care unit (ICU), severe sepsis and bacteremia) with three-level mixed logistic regression. We adjusted for possible triage bias using a propensity score and stratified the analysis by severity of disease at presentation. Results. We analyzed 266 FN episodes, including 53 (20\%) with SRE, reported in 140 of 269 patients recruited from April 2016 to August 2018. F-TTA (median, 120min; interquartile range, 49 to 180min) was not associated with SRE, with a trend for less SREs in episodes with longer F-TTA. Analyses applying the propensity score suggested a relevant triage bias. Only in patients with severe disease at presentation there was a trend for an association of longer TTA with more SRE. Conclusion. We found little evidence that longer TTA leads to a higher risk of poor clinical outcome in pediatric patients with FN, except for those with severe disease at presentation. We saw strong evidence for triage bias which could only be partially adjusted.
\end{abstract}

\section{Hosted file}

TTA Manuscript_2021.07.15.docx available at https://authorea.com/users/416218/articles/ 531224-time-to-antibiotics-in-pediatric-patients-with-fever-in-neutropenia-duringchemotherapy-for-cancer-data-from-the-prospective-multicenter-spog-2015-fn-definitionstudy 
Figure 1

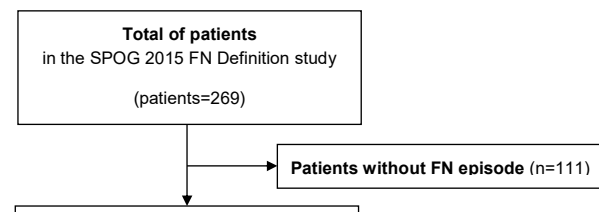

Total FN episodes

$(n=360$, with $S R E=72$, patients $=158)$

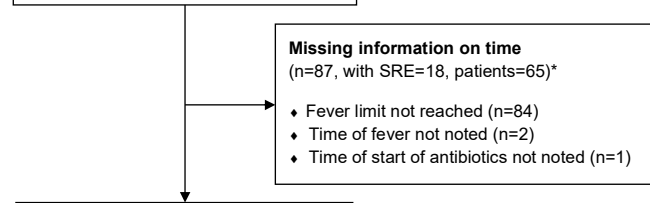

Episodes with complete information

on fever to start of antibiotics

$(n=273$, with SRE $=54$, patients $=142)$

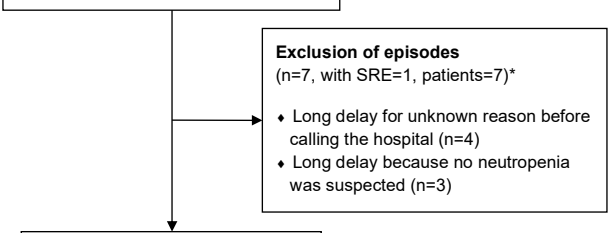

Episodes analyzed

$(n=266$, SRE $=53$, patients $=140)$

* multiple episodes per patient might apply 


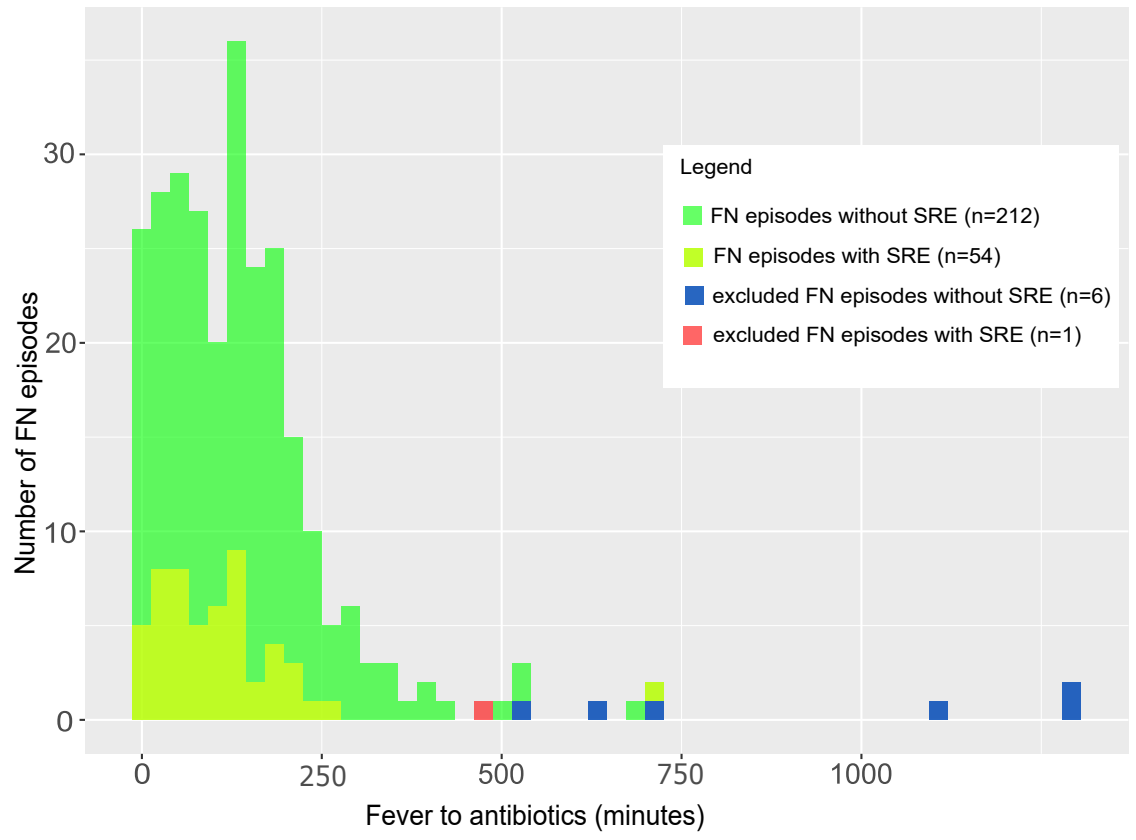


Figure 3

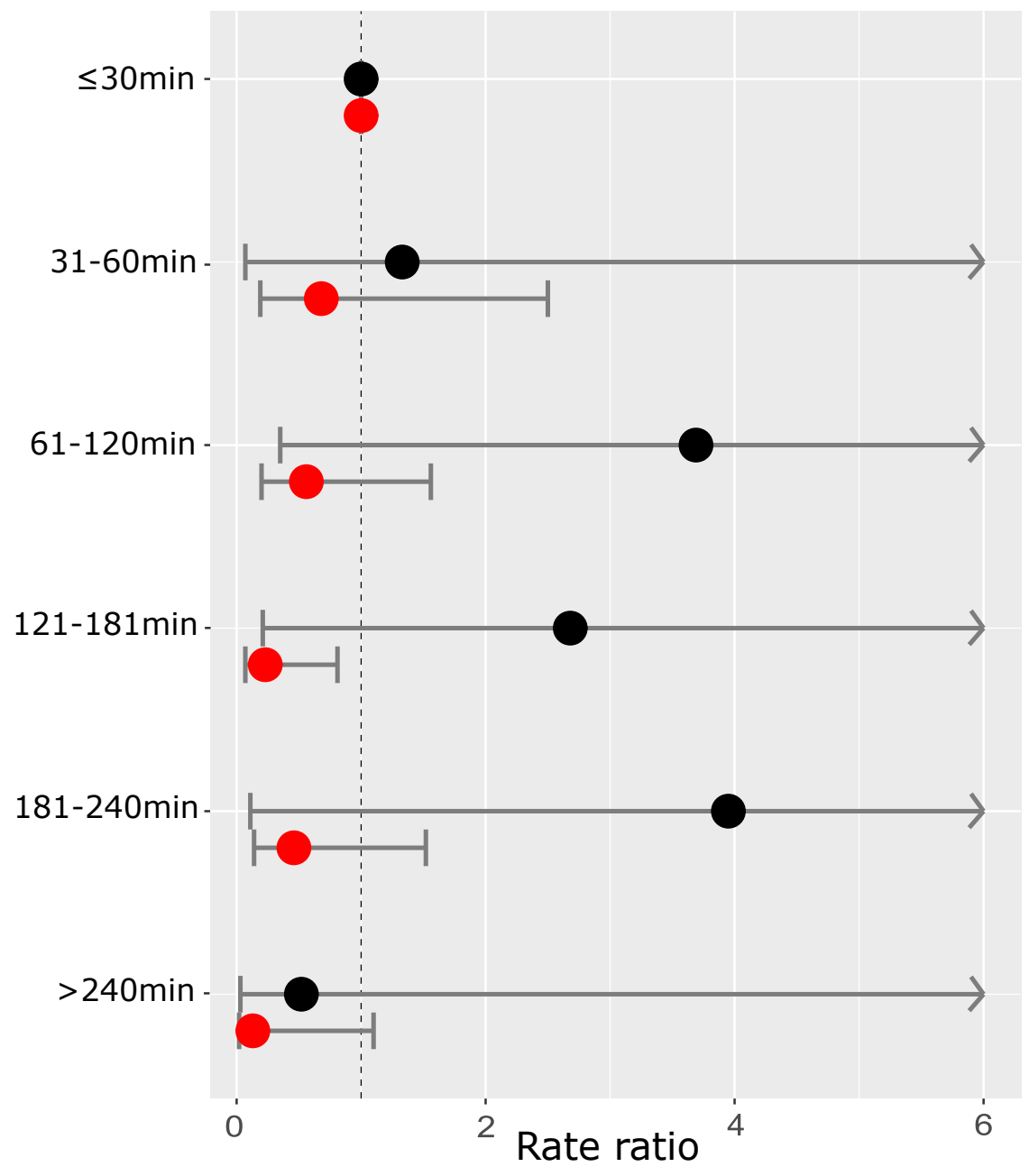




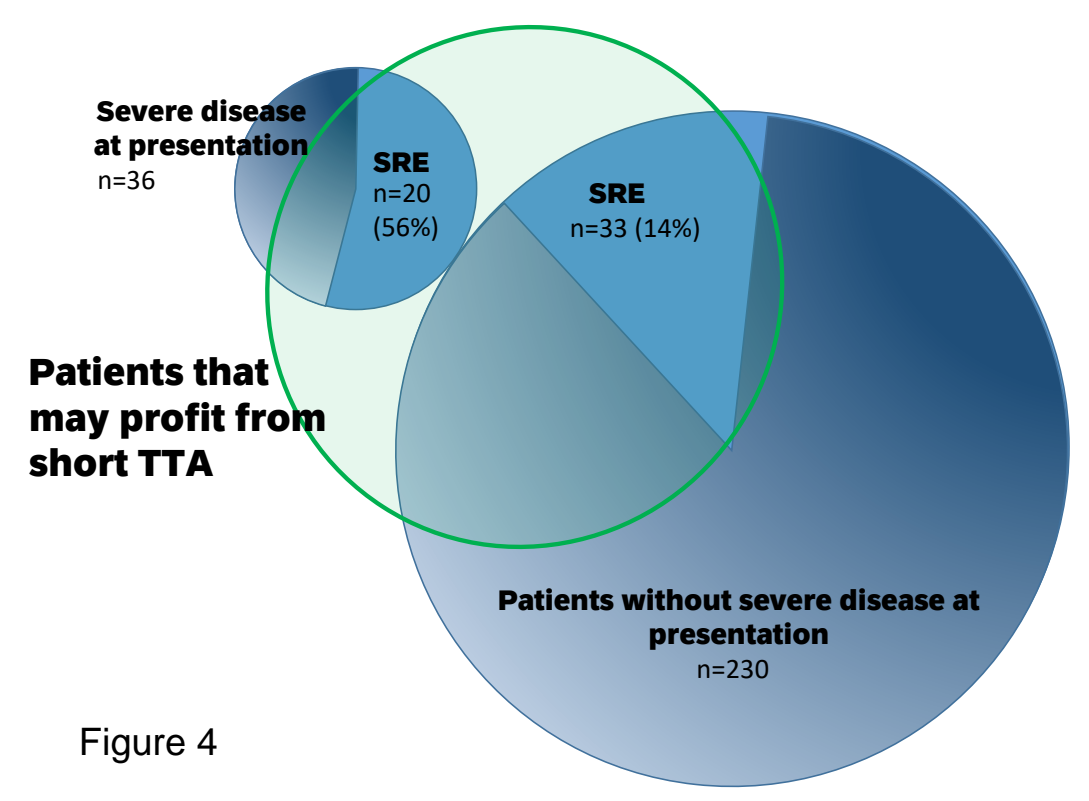

\section{Hosted file}

TTA Table 1_TLD_start_2021.07.15.docx available at https://authorea.com/users/416218/ articles/531224-time-to-antibiotics-in-pediatric-patients-with-fever-in-neutropeniaduring-chemotherapy-for-cancer-data-from-the-prospective-multicenter-spog-2015-fndefinition-study

\section{Hosted file}

TTA Table 2_TLD_start_Sepsis_2021.07.15.docx available at https://authorea.com/users/416218/ articles/531224-time-to-antibiotics-in-pediatric-patients-with-fever-in-neutropeniaduring-chemotherapy-for-cancer-data-from-the-prospective-multicenter-spog-2015-fndefinition-study 